\title{
An autosomal dominant multiple pterygium syndrome
}

\author{
C M E McKEOWN AND R HARRIS \\ From the Department of Medical Genetics, St Mary's Hospital, Manchester M13 OJH.
}

SUMMARY Three sibs and their mother with features of a multiple pterygium syndrome are reported. Inheritance in this family is consistent with autosomal dominant inheritance with greap variation in severity between affected subjects. The importance of examining other familyen members closely in cases of multiple pterygium is emphasised.

Pterygium syndromes have been described since 1880 but have proved difficult to classify. In recent years there has been renewed interest in the limb pterygium syndromes, together with further refinement in definition and classification. ${ }^{1}$ The features of multiple pterygium syndrome ${ }^{23}$ include webbing of the neck and popliteal and antecubital fossae, with associated scoliosis, syndactyly, camptodactyly, and short stature. A family, consisting of three sibs and their mother, is reported where the most severely affected member has features consistent with this multiple pterygium syndrome. Other family members have some features of the multiple pterygium syndrome in a less severe form and resemble the syndrome of multiple pterygia, ptosis, and skeletal abnormalities described by Frias et al, ${ }^{4}$ but with the additional features of short stature and mental retardation.

\section{Case reports}

CASE 1

Case 1 , the proband (III.1, fig 1), a 24 year old male, requested genetic counselling because of his scoliosis. He was the first of three children born to unrelated parents. Pregnancy, delivery, and early development were normal. He was fully active and was of normal stature until the age of 10 years when a routine medical examination revealed scoliosis. This required surgery at the age of 14 . Subsequently he has remained well and symptom free. Examination (figs 2 and 3) showed a short young man $(159 \mathrm{~cm}$, $<3$ rd centile). His intelligence appeared low normal although it has not been formally assessed. He had slightly nasal speech, a short neck, ptosis, and low

Received for publication 31 October 1986.

Revised version accepted for publication 5 January 1987
I

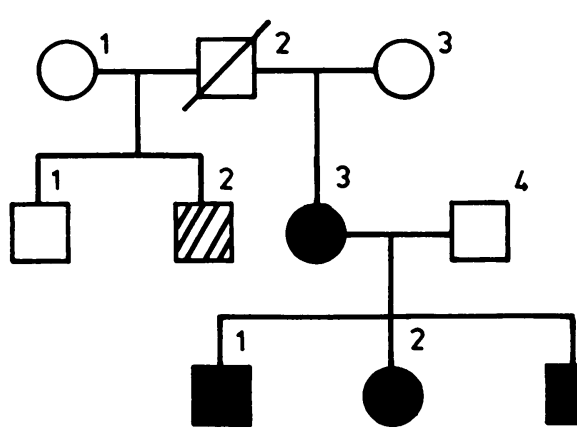

FIG 1 Family pedigree.

set, posteriorly rotated ears. The fourth and fift fingers of both hands showed camptodactyly and absent flexion creases, with bilateral transverse palmar creases (fig 4). The chest was broad with lovi set nipples. Radiology (figs 5 and 6) confirmed the presence of a severe dorsolumbar scoliosis wit several hemivertebrae at the apex of the curvature and block vertebrae at L4 and 5. There was fusion of C1 and C2 vertebrae (fig 7) with hypoplasia of the anterior arch of the atlas. The ulnar styloid was. poorly developed at both wrists and there was fusion. of the lunate and triquetrum bones. In the pelvi§ both hips were rather centrally placed with a valgu隹 deformity of the upper femora. There was hypoplaw sia of the right first sacral segment.

CASE 2 (he sister of the proband, was the result of the second pregnancy during which the mother took phenobarbitone and phenytoin foo idiopathic epilepsy. III. 2 was noted at birth to hav some syndactyly and restriction of movement of the 


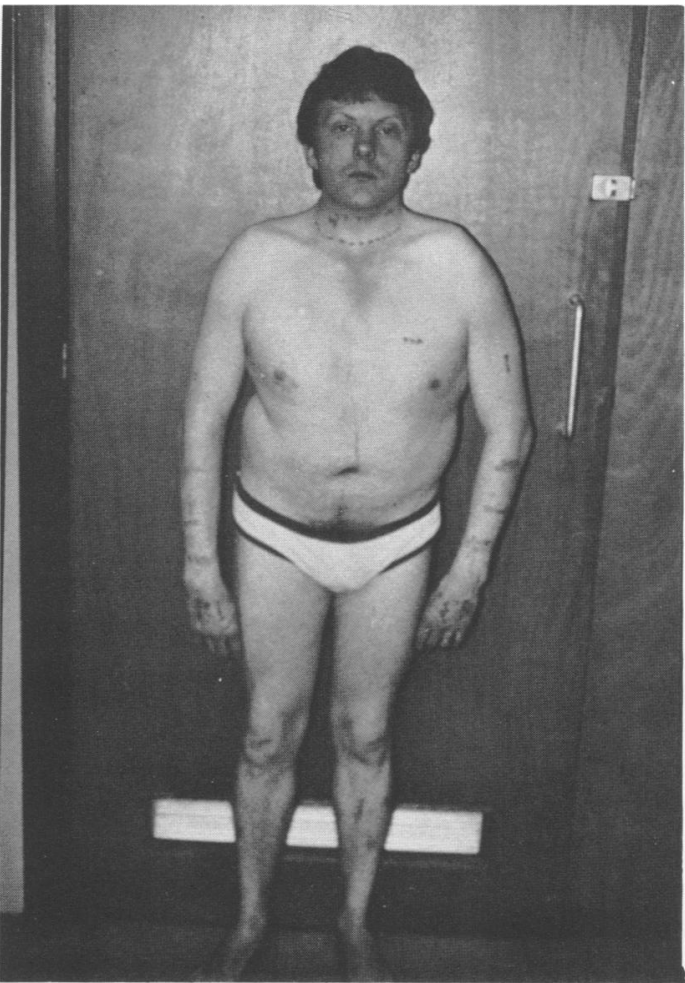

FIG 2 Case 1. Note ptosis, short neck, short stature, and low set nipples.

third and fourth fingers of the left hand. These improved with exercise. At the age of three years neck webbing was noted. She developed a scoliosis which, by the age of eight, had acquired a curve of $50^{\circ}$ when fusion and plate fixation was performed. Abnormalities of the radioulnar joints were also noted at this time. She was always smaller than her peers and more so in puberty. Sexual development was normal with menarche at 11 years. On examination at 22 years she was a woman of apparently low normal intelligence, height $150 \mathrm{~cm}$ (<3rd centile), head circumference on the 10th centile, with a short webbed neck, downward slanting palpebral fissures, ptosis, low set, posteriorly rotated ears, a high palate, and nasal speech (figs 8 and 9). There were flexion deformities of all fingers of her left hand and the fourth and fifth fingers on the right. The shoulder movements were normal in spite of some minor axillary webbing. Supination was limited. She was not examined radiologically.

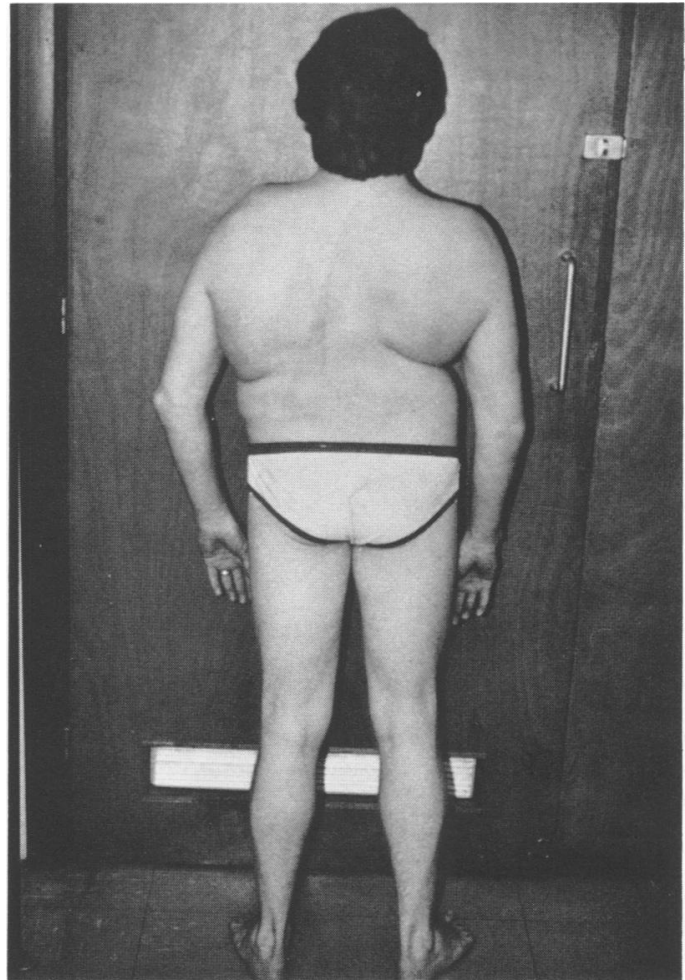

FIG 3 Case 1 showing scoliosis.

CASE 3

Case 3, III.3, the younger brother of the proband, was a small for gestational age baby, weighing $2.6 \mathrm{~kg}$ (3rd centile) at term. The pregnancy was uneventful apart from his mother's continued medication with phenobarbitone and phenytoin at the same (unknown) dose as before. Neonatally he was difficult to feed, and limitation of movement in his hands and fingers was noted. At the age of eight months he presented with bilateral inguinal herniae and was noted to have a scoliosis, abnormal ears, epicanthic folds, and possible neck webbing. He was able to sit unsupported. He walked at two and a half years and by this time his scoliosis had a curve of $22^{\circ}$, and multiple hemivertebrae had been noted. By the age of five there was definite axillary and neck webbing, radioulnar subluxation, and fixed flexion deformities of $15^{\circ}$ at the hips and $20^{\circ}$ at the knees with pterygia. At eight years he had measurably impaired respiratory function and began to develop urinary 


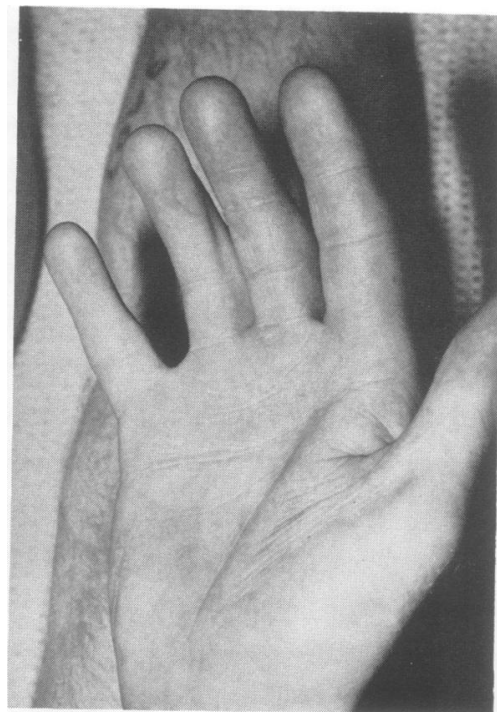

FIG 4 Hand of case 1 . Note absent flexion creases on fourth and fifth fingers, transverse palmar crease, and camptodactyly.

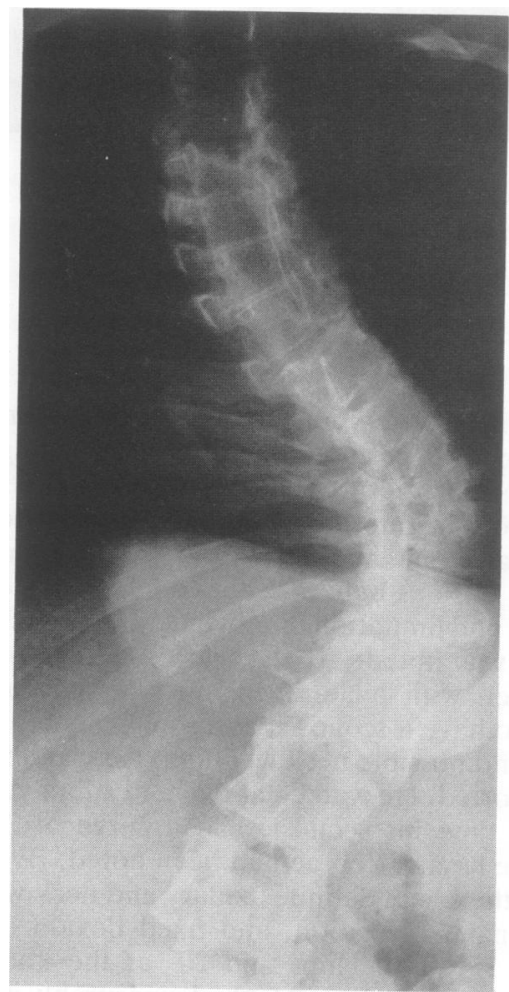

FIG 5 Case 1 showing hemivertebrae and scoliosis.
$C M E$ McKeown and $R$ Har: $\stackrel{\mathbb{D}}{\text { is }}$

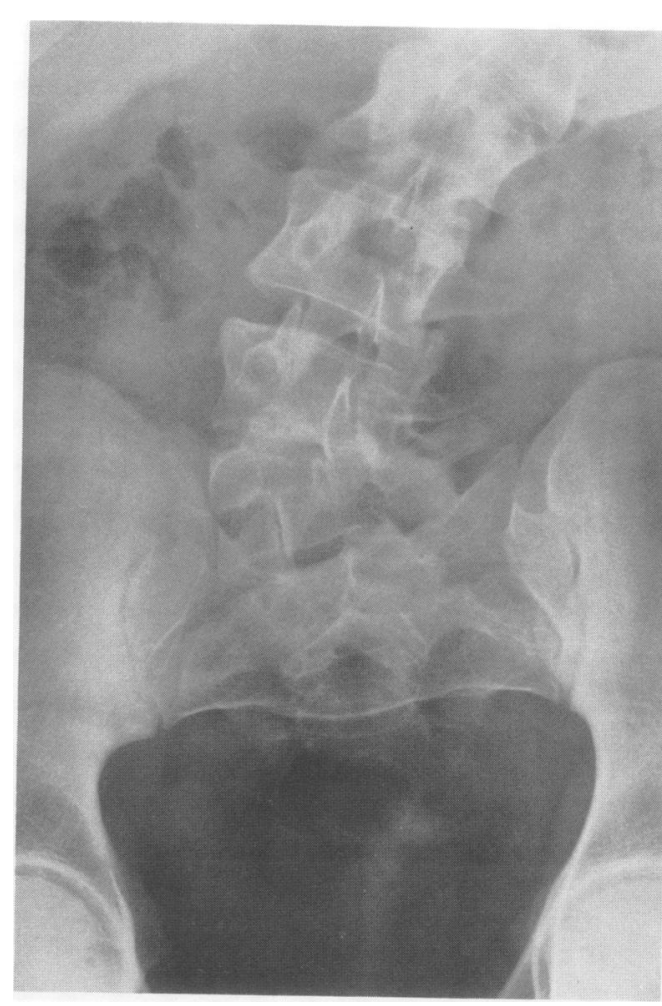

FIG 6 Case 1. Note block vertebrae at L4 and 5 and hypoplasia of the first sacral segment.

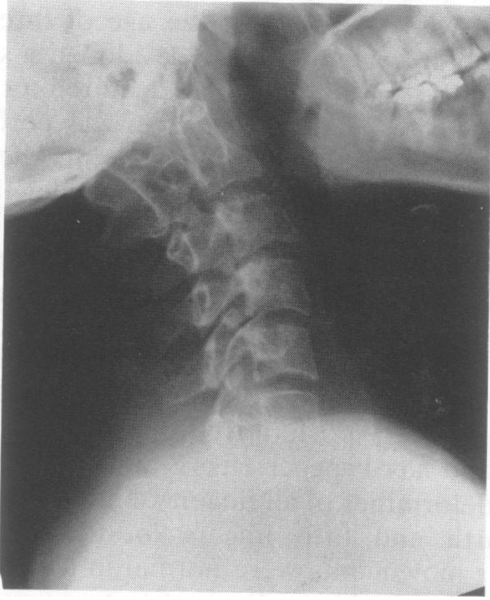

FIG 7 Case 1. Note fusion of $C 1$ and $C 2$. 


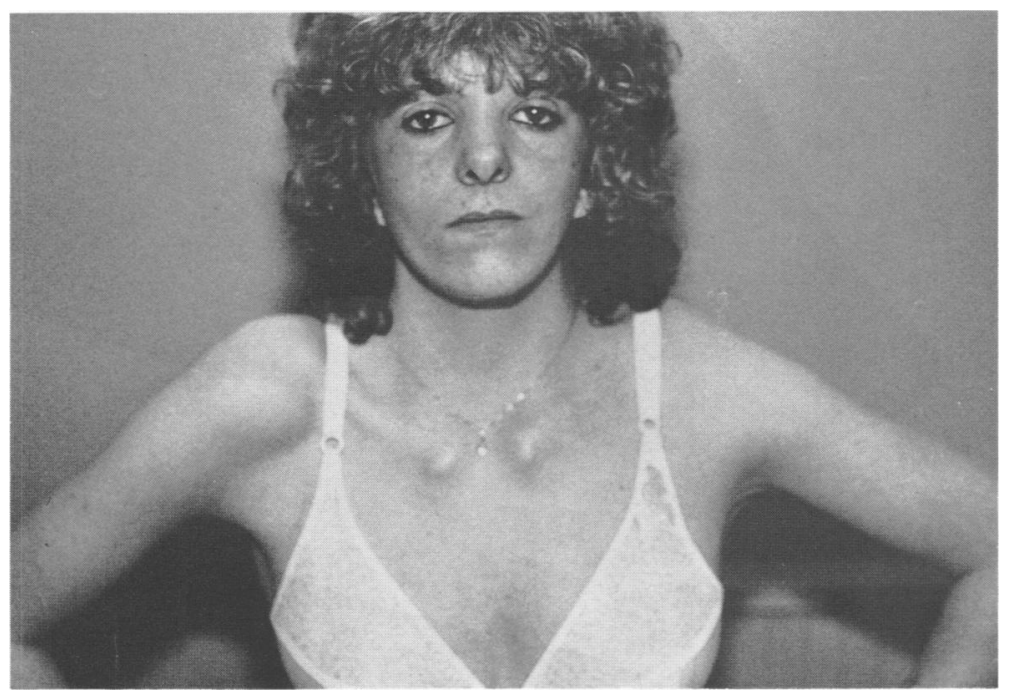

FIG 8 Case 2 showing ptosis, antimongoloid slant of the eyes, short neck, and axillary webbing on the right.

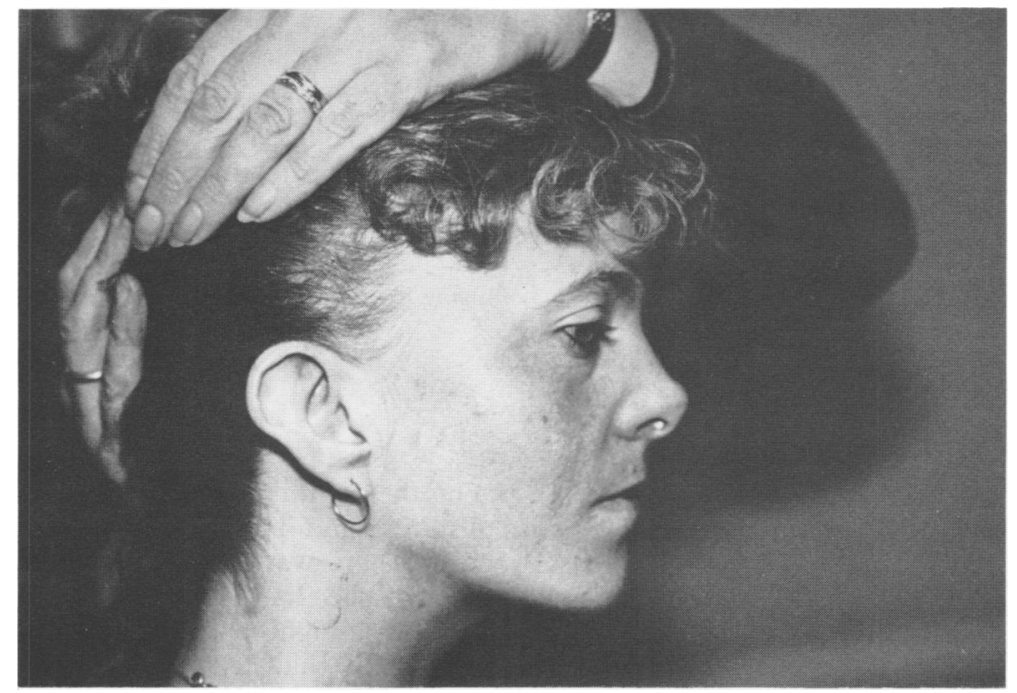

FIG 9 Case 2. Note low set, posteriorly rotated ears.

incontinence. A myelogram revealed tethering of the cord in the lower lumbar region which was released. Following this, at the age of eight and a half years, he had a Harrington rod inserted and spinal fusion for his scoliosis which by this time had a curve of $70^{\circ}$. He was assessed formally as being educationally subnormal in addition to his physical handicaps.

Examination at the age of 14 revealed a very short boy, with a height well below the 3rd centile and a head circumference on the 25 th centile and with very indistinct nasal speech. He had a short neck with marked webbing, downward slanting palpebral fissures, marked ptosis, low set, posteriorly rotated ears, and a broad palate (figs 10 and 11). In addition there was axillary, antecubital, and popliteal webbing (figs 12 and 13). There was mild soft tissue syndactyly of the first to fourth fingers of both hands and single palmar creases with absent flexion creases on some fingers (fig 14). He was prepubertal. Radiological investigation confirmed severe scoliosis with multiple hemivertebrae at the apex of the 


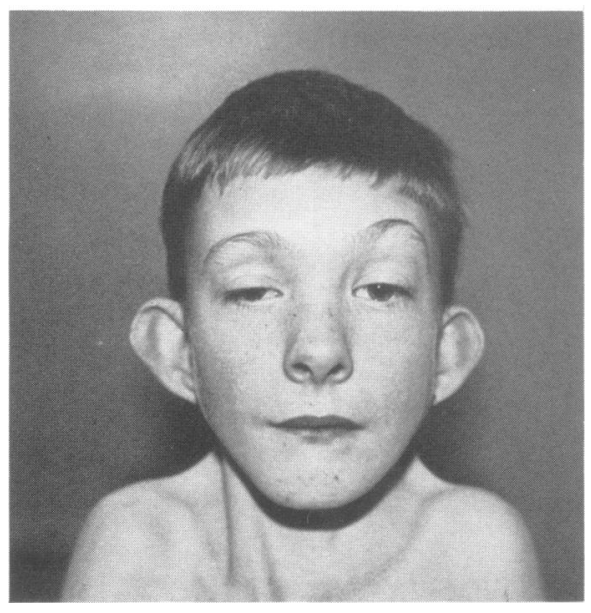

FIG 10 Case 3 showing ptosis, expressionless face, and short webbed neck.

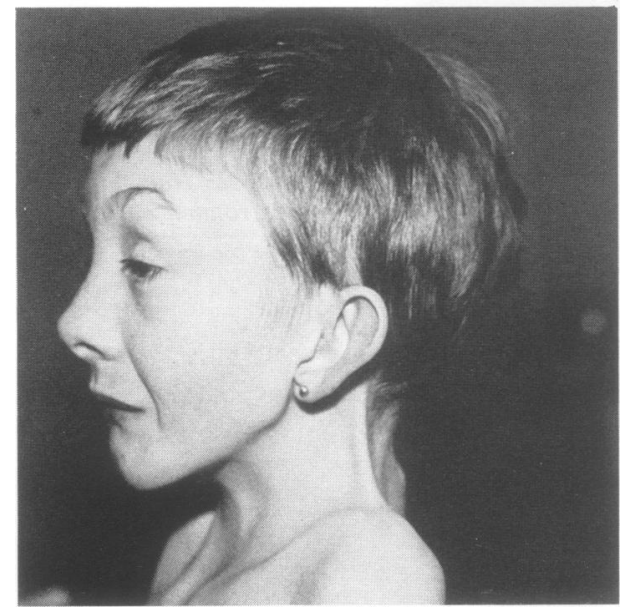

FIG 11 Case 3. Note low set, posteriorly rotated ears.

curve and spina bifida occulta of the lumbar region. The cervical spine showed fusion of $\mathrm{C} 1,2$, and 3 (fig 15). and a hypoplastic anterior arch of $\mathrm{C} 1$. In the proximal row of carpal bones there was fusion of the scaphoid and trapezium.

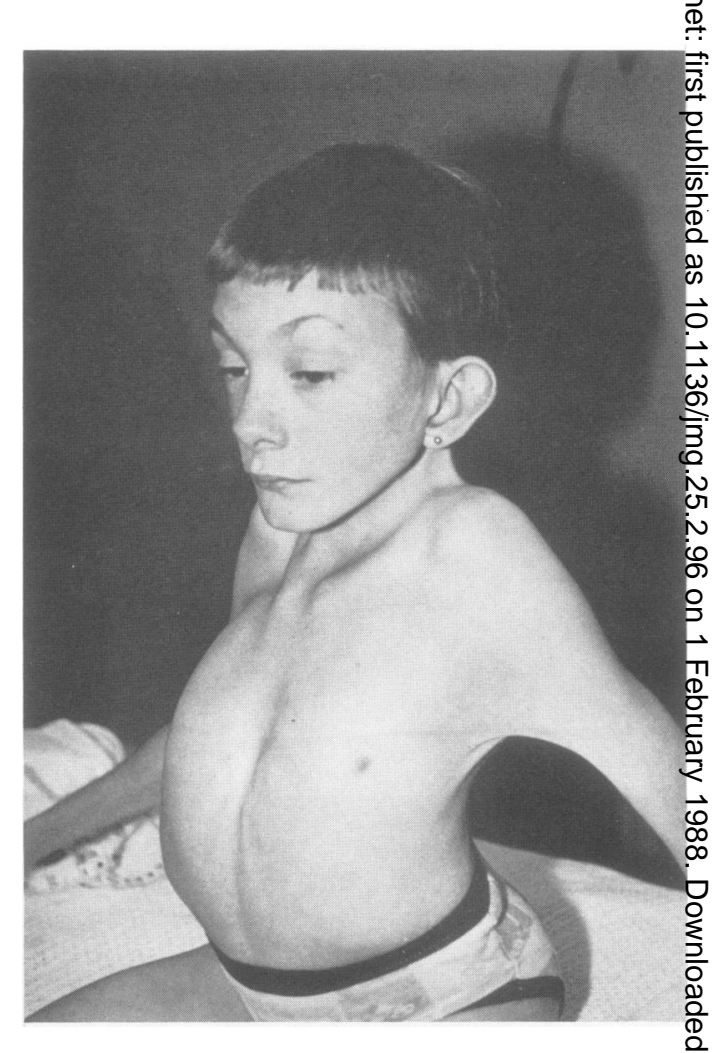

FIG 12 Case 3 showing axillary webbing and scoliosis.

CASE 4

Case 4 (II.3), the mother of the above cases, wasia woman of normal stature and intelligence, but with slightly nasal speech. There was no evidence clirically of scoliosis, but she had ptosis, low seep, posteriorly rotated ears, a high palate, and a shogt neck (figs 16 and 17). She had transverse palmar creases and flexion deformity at the proxima! interphalangeal joints in both hands together wi camptodactyly of the fourth and fifth fingers. Radiological examination showed congenityly abnormality of $\mathrm{C} 1$ and 2 with fusion of the posteribj elements. The anterior arch of the atlas wos hypoplastic and appeared fused with the irregulâgr shaped dens. There were also congenital blogk vertebrae at T10 and 11 (fig 18). $X$ rays of the hanets were unremarkable.

A brother (II.2) of case 4 (II.3) was said to hame the "family hands" but declined to be seen. The father (II.4) of cases 1,2 , and 3 was examined a apd found to be completely normal. 


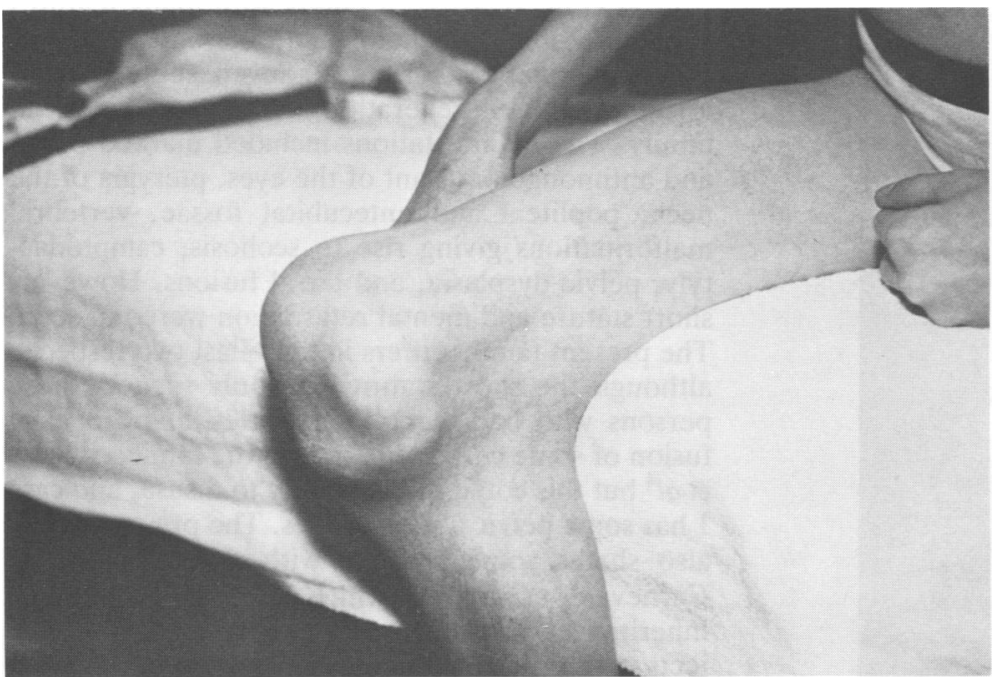

FIG 13 Case 3 showing popliteal webbing.

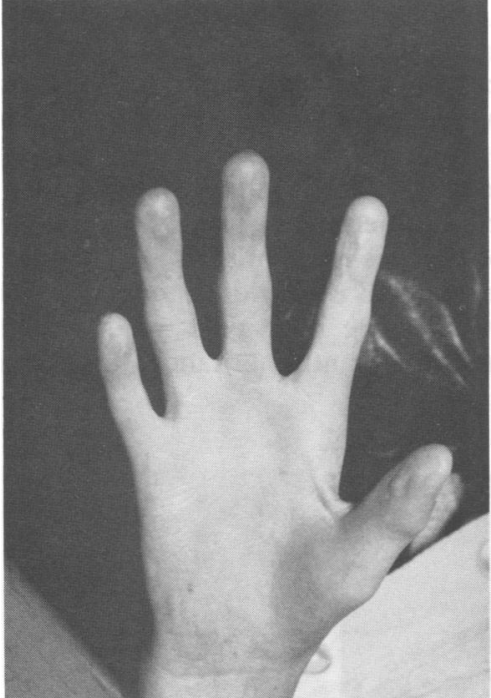

FIG 14 Case 3. Note absent flexion creases, camptodactyly, and syndactyly.

\section{Discussion}

This family shows variable expression in a dominantly inherited multiple pterygium syndrome. Cases 2 and 3 were exposed to prenatal phenobarbitone and phenytoin. The features common to the mother and all affected children are ptosis, low set, posteriorly rotated ears, a functional palate abnor- mality producing nasal speech, short neck, camptodactyly, abnormal palmar and finger creases, and vertebral abnormalities. In addition, members of this kindred show varying degrees of webbing at various joints. The clinical features of case 3, including the low birth weight with mild camptodactyly progressing to severe pterygia of neck, axillae, and antecubital and popliteal fossae, odd 


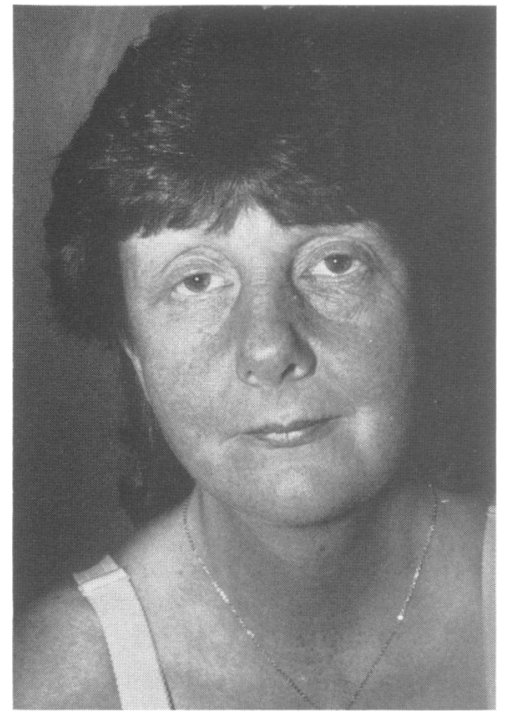

FIG 16 Case 4. Note ptosis and short neck.

facies with ptosis, palatal abnormality, short stature, mental retardation, and vertebral abnormalities, are very striking and resemble the severe sporadic cases described by Hall et al. ${ }^{1}$ These authors noted that of 49 cases reviewed, 17 were sporadic and, in general, these tended to be more severely affected. Intrafamilial variation between sibs was noted in familial cases.
Frias $e t a l^{4}$ reported a family with many features: of the multiple pterygium syndrome but with auto? somal dominant inheritance. Seven subjects were affected in three generations of a black America: family. The manifestations included marked ptos: and antimongoloid slant of the eyes, pterygia of the neck, popliteal and antecubital fossae, vertebraf malformations giving rise to scoliosis, camptodac tyly, pelvic dysplasia, and tarsal fusions. However, short stature and mental retardation were not seento The present family differs in these last two respects? although the short stature was only seen in thos persons who had a scoliosis. Cases 1 and 3 haves fusion of some carpal bones as in the family of Friass et $a l^{4}$ but this could be secondary to disuse, and case 1 has some pelvic abnormalities. The present famil also shares some features with that reported by Carnevale et $a l,{ }^{5}$ in which $\mathrm{X}$ linked dominant inheritance was inferred. The seven affected sube jects in their family had ptosis, webbing of the neclo axillae, and popliteal fossae, camptodactyly, fusea vertebrae, and scoliosis. However, severe scoliosis associated with hemivertebrae was not seen.

The most mildly affected persons in this familg might be confused with distal arthrogryposis type IIB $^{67}$ where joint contractures are associated wit ptosis. However, in this family, while there camptodactyly, there is no deviation of the fingers all affected subjects have some vertebral abnorma ties, and there is no trismus.

Because case 3 most closely resembles autosom recessive multiple pterygium syndrome, but with autosomal dominant inheritance, it is interesting

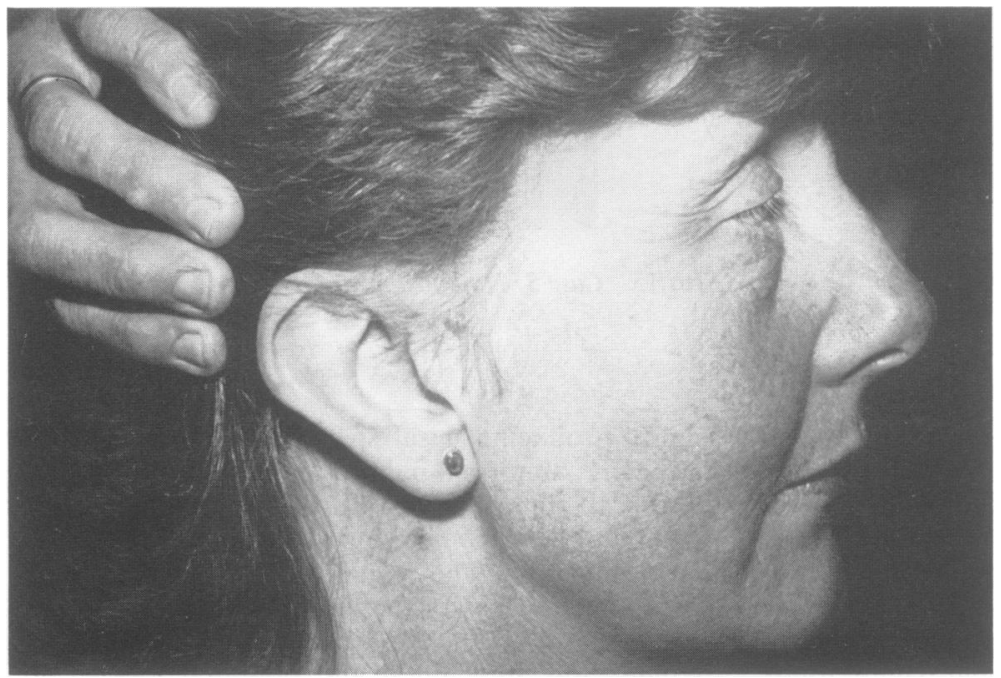

FIG 17 Case 4. Note low se posteriorly rotated ears. 


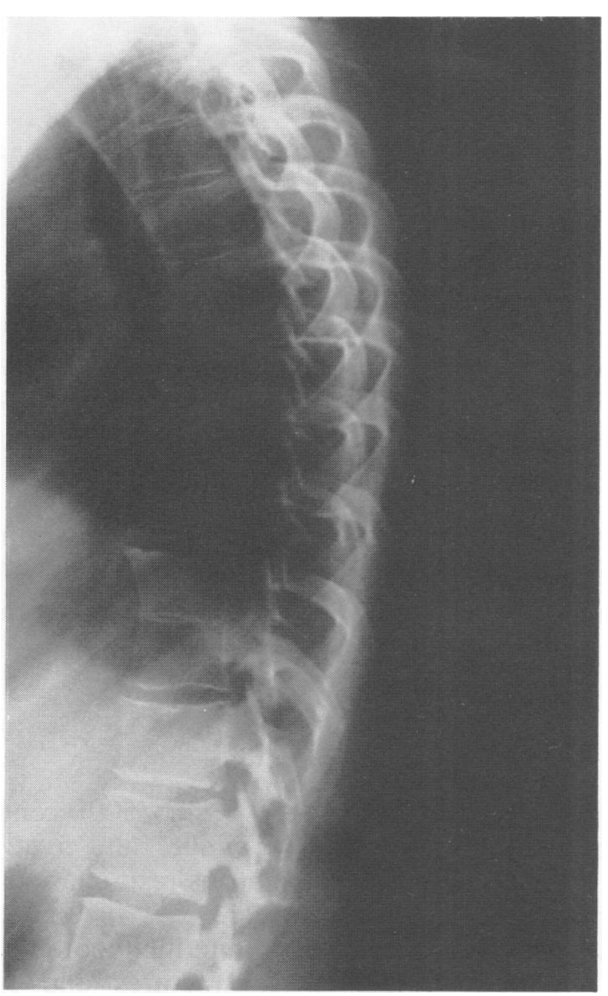

FIG 18 Case 4. Note block vertebrae at TIO and II.

speculate whether some isolated cases of multiple pterygium syndrome might not have the same condition. It is obviously important in such a situation to examine both parents closely for any minor manifestations. Such examination should include a search for minor camptodactyly, syndactyly, and ptosis, and spinal $x$ ray for asymptomatic congenital abnormalities. It is possible that fetal immobility induced by phenobarbitone and phenytoin may have played some part in the more severe expression of the phenotype in cases 2 and 3 than in 1 and 4.

\section{References}

1 Hall JG. Reed SD. Rosenbaum KN, Gershanik J, Chen H. Wilson KM. Limb pterygium syndromes: a review and report of cleven patients. Am J Med Genet 1982:12:377-409.

2 Escobar V. Bixler D. Gleiser S. Weaver DD. Gibbs T. Multiple pterygium syndrome. Am J Dis Child 1978:132:609-11.

3 Chen H, Chang CH. Misra RP. Peters HA. Crijalva NS, Opitz JM. Multiple pterygium syndrome. Am J Med Genet 1980;7: 91-1()2.

${ }^{4}$ Frias JL, Holahan JR, Rosenbloom AL, Felman AH. An autosomal dominant syndrome of multiple pterygium, ptosis and skeletal abnormalities. In: Fourth international conference on birth defects, Vienna. Amsterdam: Excerpta Medica, 1973:19.

5 Carnevale A. Hernandez AL. de los Cobos L. Sindrome de ptcrigium familiar con probablc transmission dominantc ligada al cromosoma X. Rev Invest Clin 1973:25:237-44.

"Hall JG. Recd SD. Greene G. The distal arthrogryposes: delincation of new entities-review and nosolgic discussion. Am J Med Genet 1982:11:185-239.

7 Reiss JA. Shefficld LJ. Distal arthrogryposis type II: a family with varying congenital abnormalitics. Am J Med Genet 1986; 24:255-67.

Correspondence and requests for reprints to $\mathrm{Dr} C$ McKeown, Department of Medical Genetics, St Mary's Hospital, Hathersage Road, Manchester M13 0JH. 